\title{
A review of the roles of Digital Twin in CPS-based production systems
}

\author{
Elisa Negri ${ }^{\mathrm{a} *}$, Luca Fumagalli ${ }^{\mathrm{a}}$, Marco Macchi ${ }^{\mathrm{a}}$ \\ ${ }^{a}$ Department of Management, Economics and Industrial Engineering, Politecnico di Milano, P.za Leonardo da Vinci, 32, 20133 - Milano - Italy
}

\begin{abstract}
The Digital Twin (DT) is one of the main concepts associated to the Industry 4.0 wave. This term is more and more used in industry and research initiatives; however, the scientific literature does not provide a unique definition of this concept. The paper aims at analyzing the definitions of the DT concept in scientific literature, retracing it from the initial conceptualization in the aerospace field, to the most recent interpretations in the manufacturing domain and more specifically in Industry 4.0 and smart manufacturing research. DT provides virtual representations of systems along their lifecycle. Optimizations and decisions making would then rely on the same data that are updated in real-time with the physical system, through synchronization enabled by sensors. The paper also proposes the definition of DT for Industry 4.0 manufacturing, elaborated by the European H2020 project MAYA, as a contribution to the research discussion about DT concept.
\end{abstract}

(C) 2017 The Authors. Published by Elsevier B.V. This is an open access article under the CC BY-NC-ND license (http://creativecommons.org/licenses/by-nc-nd/4.0/).

Peer-review under responsibility of the scientific committee of the 27th International Conference on Flexible Automation and Intelligent Manufacturing

Keywords: Digital Twin; Cyber-Physical Systems; Industry 4.0; Production Systems

\section{Introduction}

In the recent years, the traditional manufacturing industry is challenged worldwide with the amazing growth and advancements in digital technologies that allow easy integration of interconnected intelligent components inside the

\footnotetext{
* Corresponding author. Tel.: +390223993969

E-mail address: elisa.negri@polimi.it
} 
shopfloor, that is at the basis of the so-called Industry 4.0 and that is made possible by the widespread adoption of information and communication technologies by manufacturing companies. Industry 4.0 has been recognized at international level as one of the strategical responses of the manufacturing companies to the economic crisis, to the tendency to delocalize production and to the increased market complexity [1]. The technological basis of Industry 4.0 roots back in the Internet of Things (IoT) [2],which proposed to embed electronics, software, sensors, and network connectivity into devices (i.e. "things"), in order to allow the collection and exchange of data through the internet [3]. As such, IoT can be exploited at industrial level: devices can be sensed and controlled remotely across network infrastructures, allowing a more direct integration between the physical world and virtual systems, and resulting in higher efficiency, accuracy and economic benefits. Although it is a recent trend, Industry 4.0 has been widely discussed and its key technologies have been identified [4], among which Cyber-Physical Systems (CPS) have been proposed as smart embedded and networked systems within production systems [1,5]. They operate at virtual and physical levels interacting with and controlling physical devices, sensing and acting on the real world [6]. According to scientific literature, in order to fully exploit the potentials of CPS and IoT, proper data models should be employed, such as ontologies [7,8], which are explicit, semantic and formal conceptualizations of concepts in a domain [9]. They are the core semantic technology providing intelligence embedded in the smart CPS [10] and could help the integration and sharing of big amounts of sensed data [11,12]. Through the use of Big Data analytics, it is possible to access sensed data, through smart analytics tools, for a rapid decision making and improved productivity $[13,14]$.

With the use of these technologies, Industry 4.0 opens the way to real-time monitoring and synchronization of the real world activities to the virtual space thanks to the physical-virtual connection and the networking of CPS elements [1]. The Digital Twin (DT) is meant as the virtual and computerized counterpart of a physical system that can be used to simulate it for various purposes, exploiting a real-time synchronization of the sensed data coming from the field; such a synchronization is possible thanks to the enabling technologies of Industry 4.0 and, as such, the DT is deeply linked with it. The DT was first born in the aerospace field and only recently has been adopted also in manufacturing contexts: such a term is used in industrial environments and in governmental research initiatives; however, scientific literature that describes the contextualisation of the concept in the manufacturing domain is still at its infancy. A review of the contributions on this would be highly beneficial, in order to pave the way and clarify the conceptual foundations for future research works on the topic.

In this sense, the objective of the paper is to contribute to offer a deeper understanding of the proposed definitions of DT in scientific literature and to help in the identification of the role of the DT for manufacturing in the Industry 4.0 era. The paper is structured as follows: Section 2 deals with the research objectives and methodology; Section 3 presents the literature analysis of the Digital Twin concept and applications; Section 4 shapes the new role of the DT for Industry 4.0 manufacturing; finally, Section 5 proposes some concluding remarks.

\section{Research Statement}

According to the research motivations outlined in the Introduction, the paper aims at contributing to the shaping of the DT definition in scientific literature. This is in the direction of clarifying and extrapolating a unique definition and relevance of DT for the manufacturing sector, starting from different instances of research works in various sectors and contexts. To this aim, the paper answers the following Research Questions: "What is the definition of Digital Twin in scientific literature?" and "What is its role within Industry 4.0?".

The used methodology is a thorough literature review on the concept. In particular, the authors have searched on the Scopus Database all publications released in the five years between 2012 and 2016, that had the term "Digital Twin" in the title, abstract or in the keywords. The type of publications (Journal articles, conference papers and others) was not a filtering criteria, the only considered language was English. The reason for excluding publications before 2012 was that the main focus of the current study was the DT in relation to the Industry 4.0 that was first defined at Hannover Messe, Germany, in 2011 [15], therefore no relevant publications are to be found prior to the year 2012 with respect to these topics. 


\section{Literature analysis}

\subsection{The Digital Twin concept}

The first definition of the DT was forged by the NASA as "an integrated multi-physics, multi-scale, probabilistic simulation of a vehicle or system that uses the best available physical models, sensor updates, fleet history, etc., to mirror the life of its flying twin. It is ultra-realistic and may consider one or more important and interdependent vehicle systems": this definition first appeared in the draft and after in the final release of the NASA Modeling, Simulation, Information Technology \& Processing Roadmap in 2010 [16,17]. From that moment on, aerospace researchers started referring to the said NASA roadmap as the seminal work to define the DT (as an example [18]). As it is evident, the main scope of the original definition of the DT was to mirror the life of air vehicles with a series of integrated sub-models that reflected different aspects and vehicle systems, by considering stochasticity, historical data and sensor data, including in this way interactions of the vehicle with the real world. Only in subsequent research works, published in the same year, other aspects emerged such as the life-cycle view [19], the check on mission requirements $[19,20]$ and the use of the DT for prognostics and diagnostics activities [21], that then remained as core characteristics of the concept in future works. In 2015 with the work by Rios and colleagues [22], the definition of DT comprised a generic "Product", opening the way to the use of such a concept in other fields rather than only air vehicles, even though their work was still inserted in research about aircraft structures. Initial works in other sectors appeared even before. In fact, alongside the research in the aerospace field, in 2013 the first works reporting research on DT in manufacturing sector appeared. In particular, Lee and colleagues considered it to be the virtual counterpart of production resources, and not only of the product, setting the basis for a debate about the role of the DT in advanced manufacturing environments, such as the envisioned Industry 4.0 with its core technologies, big data analytics and cloud platforms [23]. This debate continues still today, and this work is inserted in such a stream.

To have a complete view of the definitions of the DT appeared in literature, please refer to table1.

Table 1. Definitions of Digital Twin in literature

\begin{tabular}{|c|c|c|c|}
\hline No. & Ref & Year & Definition of Digital Twin \\
\hline 1 & {$[16-$} & $\begin{array}{c}2010 \\
\text { and } \\
2012\end{array}$ & $\begin{array}{l}\text { An integrated multi-physics, multi-scale, probabilistic simulation of a vehicle or system that uses the best available } \\
\text { physical models, sensor updates, fleet history, etc., to mirror the life of its flying twin. The digital twin is ultra-realistic and } \\
\text { may consider one or more important and interdependent vehicle systems. }\end{array}$ \\
\hline 2 & {$[19]$} & 2012 & $\begin{array}{l}\text { A cradle-to-grave model of an aircraft structure's ability to meet mission requirements, including submodels of the } \\
\text { electronics, the flight controls, the propulsion system, and other subsystems }\end{array}$ \\
\hline 3 & {$[20]$} & 2012 & $\begin{array}{l}\text { Ultra-realistic, cradle-to-grave computer model of an aircraft structure that is used to assess the aircraft's ability to meet } \\
\text { mission requirements }\end{array}$ \\
\hline 4 & {$[23]$} & 2013 & $\begin{array}{l}\text { Coupled model of the real machine that operates in the cloud platform and simulates the health condition with an } \\
\text { integrated knowledge from both data driven analytical algorithms as well as other available physical knowledge }\end{array}$ \\
\hline 5 & {$[21]$} & 2013 & Ultra-high fidelity physical models of the materials and structures that control the life of a vehicle \\
\hline 6 & {$[24]$} & 2013 & Structural model which will include quantitative data of material level characteristics with high sensitivity \\
\hline 7 & {$[25]$} & 2015 & Very realistic models of the process current state and its behavior in interaction with the environment in the real world \\
\hline 8 & {$[22]$} & 2015 & Product digital counterpart of a physical product \\
\hline 9 & {$[26]$} & 2015 & $\begin{array}{l}\text { Ultra-realistic multi-physical computational models associated with each unique aircraft and combined with known flight } \\
\text { histories }\end{array}$ \\
\hline 10 & {$[27]$} & 2015 & $\begin{array}{l}\text { High- fidelity structural model that incorporates fatigue damage and presents a fairly complete digital counterpart of the } \\
\text { actual structural system of interest }\end{array}$ \\
\hline 11 & {$[28]$} & 2016 & $\begin{array}{l}\text { Virtual substitutes of real world objects consisting of virtual representations and communication capabilities making up } \\
\text { smart objects acting as intelligent nodes inside the internet of things and services }\end{array}$ \\
\hline 12 & [29] & 2016 & Digital representation of a real world object with focus on the object itself \\
\hline 13 & {$[30]$} & 016 & \\
\hline
\end{tabular}


14 [31] $2016 \quad$ Virtual representation of a real product in the context of Cyber-Physical Systems

An integrated multi-physics, multi-scale, probabilistic simulation of an as-built system, enabled by Digital Thread, that 5 [32] 2016 uses the best available models, sensor information, and input data to mirror and predict activities/performance over the life of its corresponding physical twin

A unified system model that can coordinate architecture, mechanical, electrical, software, verification, and other discipline
specific models across the system lifecycle, federating models in multiple vendor tools and configuration-controlled repositories

Research on the DT in manufacturing is an evolution of the already ongoing research stream about Virtual Factories (VF). These are defined as the digitalization of the plant integrated with the real system coming in help to the production during all the lifecycle of each asset [34]. In fact, information generated at design phase of a production system is not exploited during the operational phases, even though they could be highly valuable. This information can be used for easier performances' evaluation and management decisions during production operations. Already, works on the VF underlined the importance assumed by a proper semantic meta data model to support the necessary information structuring [35]. This was also in line with a rich manufacturing research stream dealing with the role and benefits of ontologies for production systems [36-38]. The semantic Virtual Factory Data Model (VFDM) has been developed [35], which establishes a coherent and extensible standard for the common representation of the factory entities, such as buildings, processes, products and resources, giving in this way a holistic view of the production environment [34]. The DT goes beyond the VF to include a real time synchronization with the physical system, thanks to which the user or the autonomous system can take the right decision about the actual and the future production, based on a wide range of available information. Also the DT must therefore be supported by a proper data model structuring information about the system operations, its history, its behaviour and its current state.

\subsection{The Digital Twin history}

As emerges from Table 1, despite the DT concept is recent, it has been used for different sectors and it has been linked to various aspects. A deeper investigation was deemed necessary. The authors chose to adopt a systematic search approach as described in the Section 2, "Research Statement". It emerged that the English language publications released from 2012 to 2016 listed on the Scopus Database are in total 26, and are presented in the Table 2.

From a temporal point of view, Table 2 shows that there has been an increasing interest in the DT: in fact, all references from 2012 and 2013 come from the same conference (respectively from the $53^{\text {rd }}$ and $54^{\text {th }}$ editions of the AIAA/ASME/ASCE/AHS/ASC Structures, Structural Dynamics and Materials Conference), suggesting that initially the research communities working on it were few. In 2014 there is only one paper on Scopus, while in 2015 and in 2016 the number of publications - along with the number of application fields - are increasing, respectively 5 and 12.

Publications were mainly conference papers (20), with a low number of Journal articles (5) and 1 Book Chapter. This is in line with the expectation that scientific literature on DT is very recent.

Most recent publications go beyond the boundaries of the aerospace field to reach the smart manufacturing environments, in particular related to the Industry 4.0. New technologies, such as the CPS, open the way to new uses, beyond the diagnostics and prognostics purposes, and meanings of the DT for the production systems domain. From Table 2, different possible uses emerge that have been categorized as follows:

1. The initial intended use in literature is to support health analyses for an improved maintenance activity and planning; in particular, the DT has been proposed to:

a. Monitor anomalies, fatigue, crack paths in the physical twin $[18,19,21,27,31,39,40]$;

b. Monitor geometric and plastic deformation on the material of the physical twin [41];

c. Model reliability of the physical system [20].

2. A second use with a wider scope is to digitally mirroring the life of the physical entity:

a. To study the long term behaviour of the system and predict its performances by keeping into account the different synergistic effects of environmental conditions [24,26,40,42]; 
b. To provide information continuity along the different phases of the lifecycle $[25,43]$;

c. For the Virtual Commissioning of the system [28,44];

d. To manage the lifecycle of the Internet of Things devices [29].

3. DT have been proposed to support decision making through engineering and statistical analyses $[32,45]$ :

a. Optimization of system behaviour during design phase [30,33,43,46,47];

b. Optimization of product lifecycle, knowing the past and present states, it is possible to predict and optimize the future performances $[22,45]$.

Many of the mentioned uses were targeted at improving maintenance activities, such as condition-based maintenance, diagnostics and prognostics activities. This was not only related to the use number one (health analyses), but also the other uses $[24,26,32,40,42,45]$. From this the clear vocation of the DT in its first meaning emerges as an instrument to support better prediction of failures during the system lifecycle (in particular air vehicles in the aerospace field) based on field data coming from sensors [16-18,27,31,32].

Another aspect that appeared since the very first interpretations of the DT concept was the intimate connection to simulation, that is seen in two different ways:

I. For most of the authors, the DT is a model that represents the system that different types of simulations can be based upon [19-21,25,27,28,31,33,39,44-48],

II. Others consider the DT as the simulation of the system itself [16-18,24,30,32].

Although the simulation seems to be a key aspect related to the DT concept, there are authors who do not mention it $[22,26,29,40-43,49]$. Irrespective of the connection between the two concepts, the authors mention different purposes and characteristics of the simulations and the DT. In the aerospace, the most mentioned simulations replicate the continuous time history of flights (with historical data, maintenance history information), generating enormous databases of simulations to understand what the aircraft has experienced and to forecast future maintenance needs and interventions, with the use of Finite Element Methods (FEM), Computational Fluid Dynamics (CFD), Montecarlo and Computer-Aided Engineering (CAE) applications-based simulations [19$21,27,33,46,48]$. Some authors highlight the fact that these simulations should be connected with on-board devices and sensors to have a continuous synchronization with the field condition [21]. In the robotics field, the simulations are mainly performed for the Virtual Commissioning to optimize the control algorithms for robots during development phase [28,44]. In manufacturing, the main objective of simulations are to represent the complex behaviour of the system, also considering the possible sconsequences of external factors, human interactions and design constraints $[25,30,47]$.

Also, different simulation tools have been proposed, as it is shown in Table 2.

Table 2. Results of the systematic research on Scopus

\begin{tabular}{|c|c|c|c|c|c|c|c|c|}
\hline No & Ref & Year & Type & Field & Use & Diagnostics Prognostics & Simulation & Simulation Software \\
\hline 1 & {$[49]$} & 2012 & $\mathrm{C}$ & AS & Not available & Not available & Not Available & Not available \\
\hline 2 & {$[19]$} & 2012 & $\mathrm{C}$ & AS & $\begin{array}{l}\text { As virtual health sensor, it } \\
\text { forecasts maintenance } \\
\text { needs. }\end{array}$ & Prediction of cracking & $\begin{array}{l}\text { FEM \& Montecarlo } \\
\text { Simulations }\end{array}$ & $\begin{array}{l}\text { DDSim (Damage and } \\
\text { Durability Simulator) }\end{array}$ \\
\hline 3 & {$[45]$} & 2012 & $\mathrm{C}$ & AS & $\begin{array}{l}\text { Prediction confidence; } \\
\text { decision-making in } \\
\text { condition-based } \\
\text { maintenance }\end{array}$ & $\begin{array}{l}\text { Life prediction including } \\
\text { failure }\end{array}$ & $\begin{array}{c}\text { Numerical simulation } \\
\text { (accumulation models } \\
\text { for damage and life } \\
\text { prediction) }\end{array}$ & Not available \\
\hline 4 & {$[18]$} & 2012 & $\mathrm{C}$ & AS & $\begin{array}{l}\text { Monitor manufacturing } \\
\text { anomalies }\end{array}$ & $\begin{array}{c}\text { DT for Health } \\
\text { management and } \\
\text { maintenance history }\end{array}$ & DT are simulations & Not Available \\
\hline 5 & {$[20]$} & 2012 & $\mathrm{C}$ & AS & Model reliability & $\begin{array}{l}\text { DT integrated in } \\
\text { Condition-based } \\
\text { maintenance systems }\end{array}$ & $\begin{array}{l}\text { FEM and CFD } \\
\text { simulations }\end{array}$ & $\begin{array}{c}\text { Rockstar Sim. Suite, Stick } \\
\text { to-Stress Real Time } \\
\text { Dynamic Flight Simulator } \\
\text { (S2S DFS) }\end{array}$ \\
\hline 6 & {$[41]$} & 2013 & $\mathrm{C}$ & AS & $\begin{array}{c}\text { Analyze plastic } \\
\text { deformation behavior }\end{array}$ & $\begin{array}{l}\text { Fatigue crack growth } \\
\text { prediction }\end{array}$ & No & No \\
\hline
\end{tabular}




\begin{tabular}{|c|c|c|c|c|c|c|c|c|}
\hline 7 & {$[21]$} & 2013 & $\mathrm{C}$ & AS & $\begin{array}{l}\text { Digital mirror of life of } \\
\text { physical twin }\end{array}$ & $\begin{array}{c}\text { Predictions of early } \\
\text { warnings of microcracks }\end{array}$ & $\begin{array}{l}\text { Simulation integrated } \\
\text { with on-board health } \\
\text { management system }\end{array}$ & Not available \\
\hline 8 & {$[24]$} & 2013 & $\mathrm{C}$ & AS & $\begin{array}{l}\text { Investigate long term } \\
\text { behaviour of structure } \\
\text { under multiple } \\
\text { environmental conditions }\end{array}$ & $\begin{array}{l}\text { Prognosis of structural } \\
\text { composites and their } \\
\text { synergistic response in a } \\
\text { multi-physical } \\
\text { environment }\end{array}$ & DT are simulations & Not available \\
\hline 9 & [39] & 2014 & $\mathrm{~J}$ & AS & $\begin{array}{l}\text { Monitor crack paths by } \\
\text { filling information gaps }\end{array}$ & Prediction of crack path & $\begin{array}{l}\text { Production-level } \\
\text { simulation }\end{array}$ & Not available \\
\hline 10 & {$[25]$} & 2015 & $\mathrm{C}$ & M & $\begin{array}{l}\text { Information continuity } \\
\text { along product lifecycle }\end{array}$ & Not available & $\begin{array}{l}\text { Complex behavior of } \\
\text { production }\end{array}$ & Not available \\
\hline 11 & {$[22]$} & 2015 & $\mathrm{C}$ & AS & $\begin{array}{l}\text { Simulating, predicting, } \\
\text { optimizing the product } \\
\text { lifecycle }\end{array}$ & $\begin{array}{l}\text { Maintenance services, } \\
\text { especially related to usage } \\
\text { predictions }\end{array}$ & No & No \\
\hline 12 & {$[26]$} & 2015 & $\mathrm{C}$ & AS & $\begin{array}{l}\text { Monitor and predict } \\
\text { performances }\end{array}$ & $\begin{array}{c}\text { Damage and cracks } \\
\text { detection and monitoring }\end{array}$ & No & No \\
\hline 13 & {$[48]$} & 2015 & $\mathrm{~J}$ & AS & Not available & $\begin{array}{c}\text { Diagnostics and } \\
\text { prognostics of aircrafts }\end{array}$ & $\begin{array}{l}\text { FEM \& Montecarlo } \\
\text { Simulations }\end{array}$ & Not available \\
\hline 14 & {$[27]$} & 2015 & $\mathrm{~J}$ & AS & \multicolumn{2}{|c|}{ Fatigue-damage prediction } & FEM simulation & Not available \\
\hline 15 & {$[28]$} & 2016 & $\mathrm{C}$ & $\mathrm{R}$ & Virtual Commissioning & No & $\begin{array}{l}\text { Simulations at system } \\
\text { level during design }\end{array}$ & Matlab -Simulink \\
\hline 16 & {$[29]$} & 2016 & $\mathrm{C}$ & $\mathrm{I}$ & IoT lifecycle management & No & No & No \\
\hline 17 & {$[30]$} & 2016 & $\mathrm{C}$ & M & $\begin{array}{l}\text { Optimize system behavior } \\
\text { at design }\end{array}$ & No & DT are simulations & Not available \\
\hline 18 & {$[31]$} & 2016 & $\mathrm{C}$ & M & $\begin{array}{l}\text { Monitor the physical } \\
\text { entity }\end{array}$ & No & $\begin{array}{l}\text { Data exchange } \\
\text { simulation }\end{array}$ & Not available \\
\hline 19 & {$[32]$} & 2016 & $\mathrm{C}$ & AS & $\begin{array}{l}\text { Engineering analyses and } \\
\text { decision making }\end{array}$ & $\begin{array}{l}\text { Prognosis of crack } \\
\text { propagation }\end{array}$ & $\begin{array}{l}\text { Manned flight } \\
\text { simulators }\end{array}$ & Not available \\
\hline 20 & {$[42]$} & 2016 & $\mathrm{BC}$ & AS & Defining system behavior & No & Not Available & Not available \\
\hline 21 & {$[46]$} & 2016 & $\mathrm{~J}$ & AS & Support design & Not available & Aircraft mock-up & Dassault Systemès V6 \\
\hline 22 & {$[47]$} & 2016 & $\mathrm{C}$ & $\mathrm{M}$ & Layout optimization & No & HMI interactions & Not available \\
\hline 23 & {$[43]$} & 2016 & $\mathrm{~J}$ & $\mathrm{M}$ & Data Manag. in lifecycle & No & No & No \\
\hline 24 & {$[33]$} & 2016 & $\mathrm{C}$ & AS & $\begin{array}{l}\text { Systems engineering \& } \\
\text { mechanical design integr. }\end{array}$ & No & CAE-based simulations & $\begin{array}{l}\text { Mathematica and } \\
\text { Matlab/Simulink }\end{array}$ \\
\hline 25 & {$[44]$} & 2016 & $\mathrm{C}$ & $\mathrm{R}$ & Virtual Commissioning & No & $\begin{array}{l}\text { To implement and } \\
\text { optimize the algorithm } \\
\text { for control of robots }\end{array}$ & $\begin{array}{c}\text { VEROSIM (Virtual } \\
\text { Environment and Robotic } \\
\text { Simulation) }\end{array}$ \\
\hline 26 & {$[40]$} & 2016 & $\mathrm{C}$ & AS & $\begin{array}{c}\text { Detecting failures; } \\
\text { definition of performance }\end{array}$ & Product failures detection & No & No \\
\hline
\end{tabular}

\subsection{Digital Twin in the industrial engineering}

This section is devoted to a more detailed analysis of a subset of the papers presented in Table 2, namely those applying the DT concept to the industrial engineering: thus comprising all the papers in the manufacturing and robotics sectors. Also the informatics paper was considered in this analysis because the application domain was the industrial IoT. The schematic results of this analysis are presented in Table 3, where the papers are confronted with the main aspects emerged from the previous literature on DT. 
Table 3. Analysis of the papers about Digital Twin in industrial engineering

$\begin{array}{llllll}\text { No Ref } & \text { Field } & \text { Industry 4.0 Big data } & \text { Lifecycle } & \text { SPSantic Data Model }\end{array}$

\begin{tabular}{cccccccc}
\hline 11 & {$[25]$} & M & Industry 4.0, IoT & Yes & Production system lifecycle & Yes & Meta-information and semantics \\
\hline 16 & {$[28]$} & R & Industry 4.0 & No & Complex technical systems lifecycle & No & No \\
\hline 17 & {$[29]$} & I & Industrial IoT & No & IoT lifecycle & No & No \\
\hline 18 & {$[30]$} & M & Smart CPS & No & Production system lifecycle & Yes & No \\
\hline 19 & {$[31]$} & M & Industry 4.0, IoT & Yes & Product lifecycle & Yes & AutomationML model for Data Exchange \\
\hline 23 & {$[47]$} & M & No & No & No & No & Database with CAD models \\
\hline 24 & {$[43]$} & M & Smart Products & Yes & Product lifecycle & Yes & Semantic Data Management \\
\hline 26 & {$[44]$} & R & No & No & No & No & No \\
\hline
\end{tabular}

1) The important connection between the DT concept and the Industry 4.0, mentioned in Section 1, is confirmed also by the considered papers: in fact, only two papers do not mention it [44,47], all the others name the Industry 4.0 [25,28,31] or one of the connected concepts (IoT [29], Smart CPS [30], Smart Product [43]).

2) The Big Data topic is not strongly recognized by the authors as a key aspect of the DT modeling. In fact, only Rosen recognizes that the DT model requires a huge digital data storage [25] and Schroeder carries on this argumentation stating that Big Data management and analytics become an issue in a DT context [31]. Abramovici mentions Big Data as an analysis method to elaborate data for DT-based optimizations [43].

3) The lifecycle perspective is also not shared by all authors. Some authors see the DT employed in the lifecycle of the production system $[25,30]$ or of the product $[31,43]$. Others do not adhere to the product-production system dichotomy, by considering technical system lifecycle as focus: the system is both a product (during design phase) and a production system equipment (during operations) [28,29]. The idea is that design, service and recycling/disposal phases would benefit from information generated during operations [29], stored in a unique data source [43], thus reducing effort in decision making, and in collecting data to perform simulations [28].

4) Despite the fact that the first conceptualizations of the DT did not deal with advanced manufacturing, it can be stated that the connection with the CPS is getting stronger. In fact, the papers in the manufacturing field mention the use of the DT to simulate a CPS system or product (Smart products "are cyber-physical products/systems (CPS) which use and integrate internet-based services to perform a required functionality" [43]) [25,30,31].

5) Some authors stress the importance of having a proper data model to support the named information collection and continuity during all lifecycle phases. Generally, semantic meta-data models are proposed also along product lifecycle, where semantic data management covers product lifecycle data both from the virtual and real lifecycles and their related information flow [25,43]. Schroeder sees the DT as composed of different models and data, which are aggregated in an AutomationML model for data exchange [31]. Arisoy mentions that the DT runs on a database with Computer-Aided Design (CAD) models to decide grasping point locations [47].

\section{Shaping the new role of Digital Twins for Industry 4.0 industrial engineering}

Within the European H2020 project MAYA, the research on DT of CPS-based factories has received a new impulse. MAYA proposes multi-disciplinary integrated simulation and forecasting tools, empowered by digital continuity and continuous real-world synchronization, towards reduced time to production and optimization. MAYA project aims at developing a plant DT supporting activities in all factory lifecycle phases: from the design, through the optimization of the operational life, to the dismissal phase. The central concept of the MAYA innovations is the combination of the virtual and physical dimensions with the simulation domain. The key to empower the DT representation and simulation of the actual factory lifecycle is a semantic meta-data model, describing exhaustively the CPS features. This is done through the Centralized Support Infrastructure, a platform that supports:

- The semantic meta data model, that structures information to ensure the digital continuity of data generated at all lifecycle phases of the production system;

- The simulation framework, that connects different simulation methodologies and tools for a multi-disciplinary replica of the physical system; 
- The communication layer, that ensures the seamless connection of physical CPS to the digital world, to achieve real-time synchronization and update with the huge amount of field data.

In this sense, MAYA covers all aspects related to the DT that appeared in a stronger or feebler connection in the analysed literature, in a unique framework: lifecycle perspective, information continuity through semantic meta data model, Big Data and real time synchronization with the field. Thanks to the research works performed within MAYA project, it is possible to identify the main characteristics that the DT for Industry 4.0 manufacturing systems. The DT consists of a virtual representation of a production system that is able to run on different simulation disciplines that is characterized by the synchronization between the virtual and real system, thanks to sensed data and connected smart devices, mathematical models and real time data elaboration. This is in line with the role also suggested in the aerospace field. The topical role within Industry 4.0 manufacturing systems is to exploit these features to forecast and optimize the behaviour of the production system at each life cycle phase in real time. This is fully enabled by the Industry 4.0 technologies and it is in line with the view of [50].

The MAYA approach to the DT will be demonstrated with the use of two industrial use cases: the first is a big company in the automotive sector that will exploit the DT for a quicker Virtual Commissioning of its assembly lines; the second is an SME producing cutting, bending and shearing lines for metal sheets, where the DT is useful to improve line performance evaluation and optimization.

\section{Conclusions}

The paper proposes a literature analysis about the concept of DT, in order to clarify its definition and its history, started from the aerospace field and then translated also in manufacturing applications. Although it is a highly relevant concept at industrial and research initiatives level, on the DT many elaborations and works have been proposed that did not necessarily reflect the same definition of DT. These publications are recent and mostly polarized on conference proceedings, suggesting the fact that the scientific literature is still at its infancy. For this reason, the paper contribution comes at the right moment, by offering a systematic review of what has been written on the topic and by creating a first basis for future research works on the topic. This paper in fact is aimed at clearing out the definitions given in the scientific literature and at shaping the role of the DT for Industry 4.0 manufacturing contexts, in order to motivate and analyze why and how a concept, originally born in the aerospace sector, could be beneficial to the manufacturing domain, in the presence of the technologies associated to Industry 4.0. In particular, it emerged that the relevance of DT for manufacturing industry lies in their definition as virtual counterparts of physical devices. These are digital representations based on semantic data models that allow running simulations in different disciplines, that support not only a prognostic assessment at design stage (static perspective), but also a continuous update of the virtual representation of the object by a real time synchronization with sensed data. This allows the representation to reflect the current status of the system and to perform real-time optimizations, decision making and predictive maintenance according to the sensed conditions.

The presence of already available or soon upcoming commercial software tools to support the DT creation demonstrates its importance for industry, to name a few: Predix (GE digital) (www.predix.com) and Simcenter 3D by Siemens (www.plm.automation.siemens.com/it_it/products/simcenter/3d/).

Research on Digital Twins is still at the beginning, there is a need for future research works on relevant industrial applications to investigate and demonstrate the wide range of applications and benefits where the DT could express their potential. An interesting application where the role of DT could be fundamental is the demonstration of new production control methods, see e.g. the so called Synchro-push production control policy, which has been recently formulated by [51] and that needs real-time synchronized simulations of the production system operations to be fully demonstrated, such as the DT.

\section{Acknowledgements}

This project has received funding from the European Union's Horizon 2020 research and innovation programme under grant agreement No 678556. 


\section{References}

[1] J. Lee, B. Bagheri, H. Kao, A Cyber-Physical Systems architecture for Industry 4 . 0-based manufacturing systems, Manuf. Lett. 3 (2015) 18-23. doi:10.1016/j.mfglet.2014.12.001.

[2] K. Ashton, That' Internet of Things ' Thing, RFiD J. 22 (2009) 97-114.

[3] S. Sarma, D.L. Brock, K. Ashton, The Networked Physical World, 2000.

[4] M. Brettel, N. Friederichsen, M. Keller, M. Rosenberg, How Virtualization, Decentralization and Network Building Change the Manufacturing Landscape: An Industry 4.0 Perspective, Int. J. Mech. Aerospace, Ind. Mechatronics Eng. 8 (2014) 37-44.

[5] N. Jazdi, Cyber Physical Systems in the Context of Industry 4.0, in: Autom. Qual. Testing, Robot. 2014 IEEE Int. Conf., $2014:$ pp. 1-4. doi:10.1109/AQTR.2014.6857843.

[6] R. Baheti, H. Gill, Cyber-physical Systems, in: T. Samad, A. Annaswamy (Eds.), Impact Control Technol., IEEE Control Systems Society, 2011: pp. 161-166.

[7] M. Garetti, L. Fumagalli, E. Negri, Role of Ontologies for CPS Implementation in Manufacturing, MPER - Manag. Prod. Eng. Rev. 6 (2015) 26-32. doi:10.1515/mper-2015-0033.

[8] E. Negri, L. Fumagalli, M. Garetti, L. Tanca, Requirements and languages for the semantic representation of manufacturing systems, Comput. Ind. 81 (2016) 55-66. doi:http://dx.doi.org/10.1016/j.compind.2015.10.009.

[9] T. Gruber, Toward principles for the design of ontologies used for knowledge sharing, Int. J. Hum. Comput. Stud. 43 (1995) $907-928$. http://www.sciencedirect.com/science/article/pii/S1071581985710816 (accessed September 29, 2014).

[10] C. Legat, C. Seitz, S. Lamparter, S. Feldmann, Semantics to the Shop Floor: Towards Ontology Modularization and Reuse in the Automation Domain, in: Proc. 19th IFAC World Congr., 2014: $3444-3449$. http://www.researchgate.net/publication/261361140_Semantics_to_the_Shop_Floor_Towards_Ontology_Modularization_and_Reuse_in_the Automation_Domain.

[11] $\overline{\mathrm{S}}$. Borgo, An ontological approach for reliable data integration in the industrial domain, Comput. Ind. 65 (2014) $1242-1252$. doi:10.1016/j.compind.2013.12.010.

[12] S. Heymans, L. Ma, D. Anicic, Z. Ma, N. Steinmetz, Y. Pan, J. Mei, A. Fokoue, A. Kalyanpur, A. Kerschenbaum, E. Schonberg, K. Srinivas, C. Feier, G. Hench, B. Wetzstein, U. Keller, ONTOLOGY REASONING WITH LARGE DATA REPOSITORY, in: Ontol. Manag., Springer US, 2008: pp. 89-128.

[13] J. Davis, T. Edgar, J. Porter, J. Bernaden, M. Sarli, Smart manufacturing , manufacturing intelligence and demand-dynamic performance, Comput. Chem. Eng. 47 (2012) 145-156. doi:10.1016/j.compchemeng.2012.06.037.

[14] J. Lee, H. Kao, S. Yang, Service innovation and smart analytics for Industry 4.0 and big data environment, in: Procedia CIRP, Elsevier B.V., 2014: pp. 3-8. doi:10.1016/j.procir.2014.02.001.

[15] J. Jasperneite, Was hinter Begriffen wie Industrie 4.0 steckt, Internet Und Autom. 12 (2012) 12.

[16] M. Shafto, M. Conroy, R. Doyle, E. Glaessgen, C. Kemp, J. LeMoigne, L. Wang, DRAFT Modeling, Simulation, Information Technology \& Processing Roadmap. Technology Area 11, 2010.

[17] M. Shafto, M. Conroy, R. Doyle, E. Glaessgen, C. Kemp, J. LeMoigne, L. Wang, Modeling, Simulation, Information Technology \& Processing Roadmap. Technology Area 11, 2012.

[18]E.H. Glaessgen, D.S. Stargel, The Digital Twin Paradigm for Future NASA and U. S. Air Force Vehicles, in: 53rd AIAA/ASME/ASCE/AHS/ASC Struct. Struct. Dyn. Mater. Conf., 2012: p. 1818. doi:10.2514/6.2012-1818.

[19]E.J. Tuegel, The Airframe Digital Twin: Some Challenges to Realization, in: 53rd AIAA/ASME/ASCE/AHS/ASC Struct. Struct. Dyn. Mater. Conf., 2012: p. 1812. doi:10.2514/6.2012-1812.

[20]B.T. Gockel, A.W. Tudor, M.D. Brandyberry, R.C. Penmetsa, E.J. Tuegel, Challenges with Structural Life Forecasting using Realistic Mission Profiles, in: 53rd AIAA/ASME/ASCE/AHS/ASC Struct. Struct. Dyn. Mater. Conf., 2012: p. 1813. doi:10.2514/6.2012-1813.

[21]K. Reifsnider, P. Majumdar, Multiphysics Stimulated Simulation Digital Twin Methods for Fleet Management, in: 54th AIAA/ASME/ASCE/AHS/ASC Struct. Struct. Dyn. Mater. Conf., 2013: p. 1578. doi:10.2514/6.2013-1578.

[22] J. Ríos, J.C. Hernandez, M. Oliva, F. Mas, Product Avatar as Digital Counterpart of a Physical Individual Product: Literature Review and Implications in an Aircraft, in: ISPE CE, 2015: pp. 657-666.

[23] J. Lee, E. Lapira, B. Bagheri, H. an Kao, Recent advances and trends in predictive manufacturing systems in big data environment, Manuf. Lett. 1 (2013) 38-41. doi:10.1016/j.mfglet.2013.09.005.

[24]P. Majumdar, M. FasalHaider, K. Reifsnider, Multi-physics Response of Structural Composites and Framework for Modeling Using Material Geometry, in: 54th AIAA/ASME/ASCE/AHS/ASC Struct. Struct. Dyn. Mater. Conf., 2013: p. 1577. doi:10.2514/6.2013-1577.

[25]R. Rosen, G. Von Wichert, G. Lo, K.D. Bettenhausen, About The Importance of Autonomy and Digital Twins for the Future of Manufacturing, in: IFAC-PapersOnLine, Elsevier Ltd., 2015: pp. 567-572. doi:10.1016/j.ifacol.2015.06.141.

[26]B. Bielefeldt, J. Hochhalter, D. Hartl, Computationally Efficient Analysis of SMA Sensory Particles Embedded in Complex Aerostructures Using a Substructure Approach, in: ASME Proc. - Mech. Behav. Act. Mater., 2015: pp. V001T02A007 - 10 pp.

[27] Y. Bazilevs, X. Deng, A. Korobenko, F. Lanza di Scalea, M.D. Todd, S.G. Taylor, Isogeometric Fatigue Damage Prediction in Large-Scale Composite Structures Driven by Dynamic Sensor Data, J. Appl. Mech. 82 (2015) 1-12. doi:10.1115/1.4030795.

[28] M. Schluse, J. Rossmann, From Simulation to Experimentable Digital Twins, in: Syst. Eng. (ISSE), 2016 IEEE Int. Symp., $2016:$ pp. 1-6.

[29] A. Canedo, Industrial IoT Lifecycle via Digital Twins, in: Proc. Elev. IEEE/ACM/IFIP Int. Conf. Hardware/Software Codesign Syst. Synth., 2016: p. 29.

[30]T. Gabor, L. Belzner, M. Kiermeier, M.T. Beck, A. Neitz, A Simulation-Based Architecture for Smart Cyber-Physical Systems, in: Auton. 
Comput. (ICAC), 2016 IEEE Int. Conf., 2016: pp. 374-379. doi:10.1109/ICAC.2016.29.

[31] G.N. Schroeder, C. Steinmetz, C.E. Pereira, E.D. B., Digital Twin Data Modeling with AutomationML and a Communication Methodology for Data Exchange, in: IFAC-PapersOnLine, Elsevier B.V., 2016: pp. 12-17. doi:10.1016/j.ifacol.2016.11.115.

[32]E.M. Kraft, The US Air Force Digital Thread / Digital Twin - Life Cycle Integration and Use of Computational and Experimental Knowledge II . The Evolution of Integrated Computational / Experimental Fluid Dynamics, in: 54th AIAA Aerosp. Sci. Meet., 2016: pp. 122. doi:10.2514/6.2016-0897.

[33]M. Bajaj, D. Zwemer, B. Cole, Architecture to Geometry - Integrating System Models with, in: AIAA Sp. Forum, 2016: pp. 1-19. doi: $10.2514 / 6.2016-5470$.

[34] M. Sacco, P. Pedrazzoli, W. Terkaj, VFF : Virtual Factory Framework, in: Technol. Manag. Conf. (ICE), 2010 IEEE Int., 2010 : pp. 1-8.

[35]W. Terkaj, M. Urgo, Ontology-based Modeling of Production Systems for Design and Performance Evaluation, in: Ind. Informatics (INDIN), 2014 12th IEEE Int. Conf., 2014: pp. 748-753.

[36] M. Garetti, L. Fumagalli, Role of ontologies in open automation of manufacturing systems, in: Proc. XVII Summer Sch. Ind. Mech. Plants 12/9/2012-14/9/2012, Venice, Italy, 2012.

[37]E. Negri, L. Fumagalli, M. Macchi, M. Garetti, Ontology for Service-Based Control of Production Systems, in: APMS 2015, Part II, IFIP AICT 460, 2015: pp. 484 - 492. http://www.springerlink.com/index/10.1007/978-1-4020-9783-6.

[38]L. Fumagalli, S. Pala, M. Garetti, E. Negri, Ontology-based modeling of manufacturing and logistics systems for a new MES architecture, in: APMS 2014, IFIP Adv. Inf. Commun. Technol. 438 (PART I), 2014: pp. 192-200.

[39] A. Cerrone, J. Hochhalter, G. Heber, A. Ingraffea, On the Effects of Modeling As-Manufactured Geometry: Toward Digital Twin, Int. J. Aerosp. Eng. 2014 (2014) 1-10.

[40]E. Fourgeau, E. Gomez, H. Adli, C. Fernandes, M. Hagege, System Engineering Workbench for Multi - views Systems Methodology with 3DEXPERIENCE Platform. The Aircraft RADAR Use Case, Complex Syst. Des. Manag. Asia. 426 (2016) 269-270. doi:10.1007/978.

[41]J. Yang, W. Zhang, Y. Liu, Subcycle Fatigue Crack Growth Mechanism Investigation for Aluminum Alloys and Steel (Special Session on the Digital Twin), in: 54th AIAA/ASME/ASCE/AHS/ASC Struct. Struct. Dyn. Mater. Conf., 2013: p. 1499. doi:10.2514/6.2013-1499.

[42]M. Grieves, J. Vickers, Digital Twin: Mitigating Unpredictable, Undesirable Emergent Behavior in Complex Systems, in: Transdiscipl. Perspect. Complex Syst., 2016: pp. 85-113. doi:10.1007/978.

[43] M. Abramovici, J.C. Gobel, H.B. Dang, Semantic data management for the development and continuous reconfiguration of smart products and systems, CIRP Ann. - Manuf. Technol. 65 (2016) 185-188. doi:10.1016/j.cirp.2016.04.051.

[44] G. Grinshpun, T. Cichon, D. Dipika, J. Roßmann, From Virtual Testbeds to Real Lightweight Robots: Development and deployment of control algorithms for soft robots, with particular reference to industrial peg-in-hole insertion tasks, in: ISR 2016 47st Int. Symp. Robot. Proc., 2016: pp. 208-214.

[45]B.P. Smarslok, A.J. Culler, S. Mahadevan, Error Quantification and Confidence Assessment of Aerothermal Model Predictions for Hypersonic Aircraft, in: 53rd AIAA/ASME/ASCE/AHS/ASC Struct. Struct. Dyn. Mater. Conf., 2012: p. 1817. doi:10.2514/6.2012-1817.

[46] J. Ríos, F.M. Morate, M. Oliva, J.C. Hernández, Framework to support the aircraft digital counterpart concept with an industrial design view, Int. J. Agil. Systsems Manag. 9 (2016) 212-231. doi:10.1504/IJASM.2016.079934.

[47]E.B. Arisoy, G. Ren, E. Ulu, N.G. Ulu, S. Musuvathy, A Data - Driven Approach to Predict Hand Positions for Two - Hand Grasps of Industrial Objects, in: ASME 2016 Int. Des. Eng. Tech. Conf. Comput. Inf. Eng. Conf., 2017: pp. V01AR02A067 - 11 pp. doi:10.1115/DETC2016.

[48]H.-K. Wang, R. Haynes, H.-Z. Huang, L. Dong, S.N. Atluri, The Use of High-Performance Fatigue Mechanics and the Extended Kalman / Particle Filters, for Diagnostics and Prognostics of Aircraft Structures, C. Comput. Model. Eng. Sci. 105 (2015) 1-24.

[49]P. Holzwarth, R. Tuegel, E. Kobryn, Airframe digital twin: An overview, in: Progn. Heal. Manag. Solut. Conf. MFPT 2012, 2012 : p. 20.

[50]M. Garetti, P. Rosa, S. Terzi, Life Cycle Simulation for the design of Product-Service Systems, Comput. Ind. 63 (2012) $361-369$. doi:10.1016/j.compind.2012.02.007.

[51]M. Garetti, M. Macchi, A. Pozzetti, L. Fumagalli, E. Negri, Synchro-push: a new production control paradigm, in: 21st Summer Sch. Fr. Turco 2016, 2016: pp. 150-155. 